\title{
The Research of Gas Flooding of Horizontal Well with SRV in Tight Oil Reservoir
}

\author{
Xiaoliang Zhao*, Xinwei Liao and Huan Wang \\ China University of Petroleum-Beijing, China
}

\begin{abstract}
The characteristics of tight oil reservoir are low porosity and ultra-low permeability, thus stimulated reservoir volume (SRV) should be conducted whether applying the mode of vertical wells or horizontal wells production Tight oil reservoir is mostly developed by natural depletion or water flooding recently, but the problems are existed, including low recovery factor with natural depletion and the difficulty of water injection. To further improve the development effect of tight oil reservoir, $\mathrm{CO}_{2}$ flooding is proposed. Based on changing tight oil reservoir in Ordos Basin, an oil sample of typical block is selected. The PVT experiments are conducted. The compositional numerical model of five-spot pattern is established with a horizontal well in the middle and 4 vertical wells on the edge. Based on the model, several $\mathrm{CO}_{2}$ flooding scenarios of horizontal well with different completion measures are studied. Furthermore, parameters such as the formation pressure, production rate, shut-in gas-oil ratio and total gas injection volume are optimized. The results of this study show that the recovery factor of horizontal well with SRV is higher than those of horizontal well and conventional fractured horizontal well. The study gives new ideas of $\mathrm{CO}_{2}$ flooding with volume fractured horizontal well for the Ordos Basin tight oil reservoir. It can be helpful for rapid and effective development of tight oil reservoirs in Ordos Basin.
\end{abstract}

Keywords: $\mathrm{CO}_{2}$ flooding; Tight oil reservoir; Gas flooding

\section{Introduction}

In recent years, it is become a hot spot to develop unconventional reservoirs, such as tight oil, tight gas and shale gas [1,2]. Tight oil is a typical unconventional resource, which has the characteristics of good fluid properties and poor reservoir properties. The permeability and porosity of tight oil reservoir are general less than $1 \times 10^{3} \mu \mathrm{m}^{2}$ and $10 \%$, respectively [3]. Currently, the unconventional reservoirs are usually developed by horizontal wells, especially the segmented multi-cluster fractured horizontal wells, which have been widely used worldwide [4]. The simulated reservoir volume (SRV) can be formed around the horizontal well after segmented multi-cluster fracturing $[5,6]$. The technology of SRV is to achieve the important goal of increasing the contact area between matrix and fractures or fracture network as far as possible during the development of unconventional reservoirs $[7,8]$. The study and application of developing tight oil and shale oil reservoirs mostly focus on the natural depletion [9]. But some studies have shown that $\mathrm{CO}_{2}$ flooding is an effective approach of enhanced oil recovery $(\mathrm{EOR})$ in tight reservoirs $[6,10,11]$. Based on the real case of Changqing tight oil reservoir in Ordos Basin, both PVT experiments and minimum miscible pressure (MMP) experiments were conducted for the crude oil sample of typical block. The compositional numerical model of typical five-spot well group is built, which is used to study the water flooding, $\mathrm{CO}_{2}$ flooding and Water-Alternate-Gas (WAG) of $\mathrm{CO}_{2}$ flooding. Different completion measures of horizontal well are analyzed. Furthermore, parameters such as the formation pressure, production rate, shut-in gas-oil ratio and total gas injection volume are analyzed. "Gas Flooding," also known as miscible flooding, is one of the leading enhanced oil recovery (EOR) technologies employed for recovering oil that was formerly referred to as either stranded or trapped. Gas flooding is an "enhanced oil recovery" application for injecting miscible (and immiscible) gases into an oil reservoir for increasing oil production.

Gas flooding typically includes $\mathrm{CO}_{2}$, natural gas or nitrogen as the gas that is injected. Gas flooding tasked place as either a miscible flood or an immiscible flood. Miscible means that the gas that is injected "mixes" with the oil, thereby reducing viscosity and interfacial tension of the oil and rock. Miscible gas flooding also increases oil "swelling" and localized pressure or drive within the reservoir. "Immiscible" flooding means that the gas that is injected into the reservoir does not mix or go into solution. Therefore the purpose of the immiscible flood is to provide the energy or drive by increased pressure. Immiscible flooding does not produce as much oil as miscible gs flooding, however there are certain applications and reservoirs wherein immiscible flooding is well-suited.

\section{Reservoir Characteristics and Numerical Simulation Model}

\section{PVT and MMP experiments}

A crude oil sample is obtained in the tight oil reservoir. The PVT experiments are also conducted, and PR3 equation of state (EOS) is applied in PVT regression via PVTi module of Eclipse 2010 to match the experimental data of single flash vaporization test, differential liberation (DL) experiment and constant composition expansion (CCE) experiment. 9 pseudo-components of crude oil are grouped and their mole fractions are shown in Table 1 . The parameters are well matched to meet the accuracy required for simulation (Table 2). It illustrates that the critical parameters of fluid can reflect the characters of real reservoir fluid.

Slim tube experiment of the crude oil sample is conducted. The result shows that the $\mathrm{CO}_{2}$ minimum miscible pressure (MMP) of the crude oil and $\mathrm{CO}_{2}$ is $19.8 \mathrm{MPa}$ (Figure 1).

*Corresponding author: Xiaoliang Zhao, China University of Petroleum-Beijing China, Tel: 86-10-8973-3266; E-mail: zxl@cup.edu.cn

Received September 24, 2014; Accepted October 30, 2014; Published November 10, 2014

Citation: Zhao X, Liao X, Wang H (2015) The Research of Gas Flooding of Horizontal Well with SRV in Tight Oil Reservoir. J Pet Environ Biotechnol 5: 197. doi:10.4172/2157-7463.1000197

Copyright: ( 2015 Zhao X, et al. This is an open-access article distributed under the terms of the Creative Commons Attribution License, which permits unrestricted use, distribution, and reproduction in any medium, provided the original author and source are credited. 
Citation: Zhao X, Liao X, Wang H (2015) The Research of Gas Flooding of Horizontal Well with SRV in Tight Oil Reservoir. J Pet Environ Biotechnol 6: 197. doi:10.4172/2157-7463.1000197

Page 2 of 4

\begin{tabular}{|c|c|c|c|c|c|c|c|c|c|}
\hline Pseudo-component & $\mathrm{CO}_{2}$ & $\mathrm{~N} 2+\mathrm{C} 1$ & $\mathrm{C} 2$ & C3-nC4 & C5-C6 & C7-C10 & C11-C17 & C18-C27 & $\mathrm{C} 28+$ \\
\hline Mole fraction (\%) & 0.05 & 24.64 & 7.83 & 16.99 & 5.69 & 10.96 & 15.59 & 9.62 & 8.62 \\
\hline
\end{tabular}

Table 1: Pseudo-components of crude oil sample.

\begin{tabular}{|c|c|c|c|c|c|c|c|}
\hline Components & $\mathrm{MW}(\mathrm{g} / \mathrm{mol})$ & $\mathbf{P}_{c}$ (bar) & $\mathrm{T}_{\mathrm{c}}(\mathrm{K})$ & $V_{c}\left(m^{3} /(k g \cdot m o l)\right)$ & $\Omega \mathbf{a}$ & $\Omega b$ & AF \\
\hline $\mathrm{CO}_{2}$ & 44.010 & 73.866 & 304.700 & 0.094 & 0.457 & 0.078 & 0.225 \\
\hline $\mathrm{N} 2+\mathrm{C} 1$ & 16.563 & 76.650 & 203.786 & 0.098 & 0.457 & 0.078 & 0.014 \\
\hline $\mathrm{C} 2$ & 30.070 & 48.839 & 305.430 & 0.148 & 0.457 & 0.078 & 0.099 \\
\hline $\mathrm{C} 3+$ & 49.369 & 71.279 & 339.297 & 0.221 & 0.830 & 0.062 & 0.169 \\
\hline $\mathrm{C} 5+$ & 75.871 & 32.621 & 479.106 & 0.323 & 0.457 & 0.078 & 0.260 \\
\hline $\mathrm{C} 7+$ & 120.118 & 74.482 & 1408.507 & 0.482 & 0.274 & 0.132 & 0.044 \\
\hline $\mathrm{C} 11+$ & 185.069 & 73.427 & 1636.818 & 0.712 & 0.457 & 0.132 & 0.064 \\
\hline C18+ & 303.675 & 67.394 & 1902.062 & 1.065 & 0.457 & 0.171 & 0.093 \\
\hline $\mathrm{C} 28+$ & 572.433 & 39.176 & 2356.645 & 2.187 & 0.171 & 0.087 & 0.183 \\
\hline
\end{tabular}

Table 2: Fluid parameters after regression.

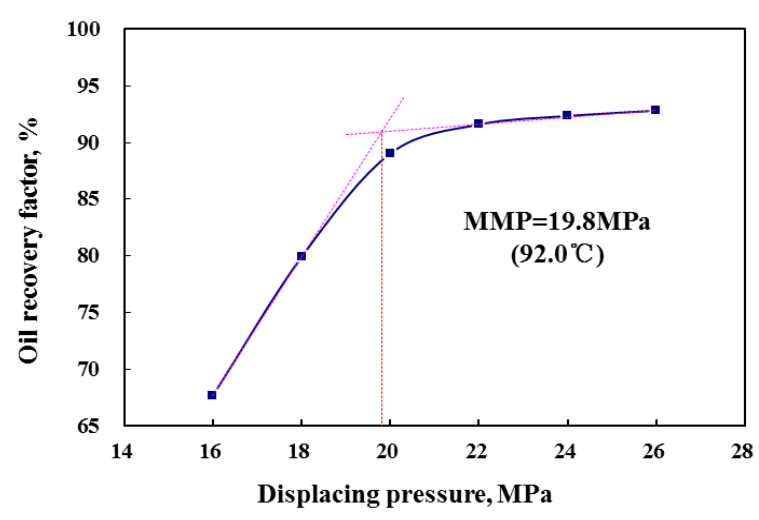

Figure 1: Experimental result of MMP for $\mathrm{CO}_{2}$ flooding.
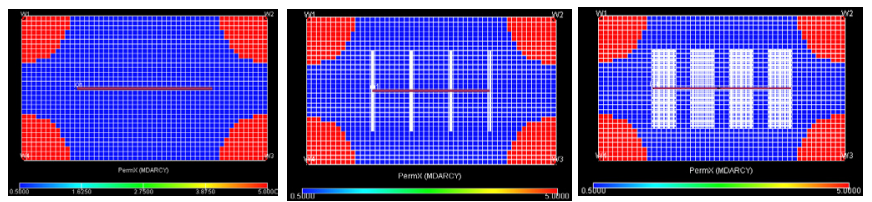

Figure 2: Numerical simulation models (left: model 1, middle: model 2, right: model 3).

\begin{tabular}{|c|c|c|c|}
\hline Parameters & Value & Parameters & Value \\
\hline Grid spacing, $\mathrm{m}$ & $20^{\star} 20^{\star} 2$ & Irreducible water saturation & 0.43 \\
\hline Grid dimension & $51^{*} 31^{\star} 5$ & Initial reservoir pressure, $\mathrm{MPa}$ & 19.2 \\
\hline Geologic reserve, $10^{4} \mathrm{t}$ & 26.14 & Saturation pressure, $\mathrm{MPa}$ & 9.25 \\
\hline Temperature ${ }^{\circ} \mathrm{C}$ & 80 & Initial gas/oil ratio, $\mathrm{m}^{3} / \mathrm{m}^{3}$ & 68.17 \\
\hline Reservoir depth, $\mathrm{m}$ & 2540 & Oil volume factor & 1.297 \\
\hline Effective thickness, $\mathrm{m}$ & 10 & Density of surface oil, $\mathrm{kg} / \mathrm{m}^{3}$ & 851.0 \\
\hline Porosity, $\%$ & 8.8 & Density of formation oil, $\mathrm{kg} / \mathrm{m}^{3}$ & 733.0 \\
\hline Permeability, $\mathrm{mD}$ & 0.5 & Viscosity of formation oil, $\mathrm{mPa} \cdot \mathrm{s}$ & 1.4 \\
\hline Kv/Kh & 0.1 & Conductivity of bi-wing fracture, $\mathrm{mD} \cdot \mathrm{m}$ & 400 \\
\hline Initial oil saturation & 0.6 & Conductivity of fracture network, $\mathrm{mD} \cdot \mathrm{m}$ & 30 \\
\hline
\end{tabular}

Table 3: Parameters of numerical simulation model.

\section{Numerical simulation model}

Based on the tight oil reservoir, three numerical models of fivespot well groups with SRV are built. Model 1, a perforated horizontal well without fracturing located in the middle of the well group and the length of the horizontal section is $540 \mathrm{~m}$ (Figure 2, model 1). Model 2 , there are a hydraulic fracturing horizontal well with three bi-wing transverse fractures in the toe, middle and heel of the well, respectively (Figure 2, model 2), and the location and length of model 2 are the same as model 1 . Model 3, a $540 \mathrm{~m}$ length horizontal well located in the middle of the well group. The horizontal well has been segmented multi-cluster fractured and formed four $100 \mathrm{~m} \times 180 \mathrm{~m} \times 10 \mathrm{~m}$ SRVs around the wellbore (Figure 2, model 3). Four vertical wells are located around them for each model. In this paper, the geometry of fracture extension is assumed to be wire-mesh networks, which forms a rule rectangular fracture network after fracturing. In order to guarantee the convergence in simulation and achieve the rectangular fracture propagation, the grids with width of $0.1 \mathrm{~m}$ after local grid refinement (LGR) are set to fractures. Vertical wells are also volume fractured to increase their injectivity, which is simulated simply by changing the reservoir permeability around them. Detailed parameters of these numerical models are shown in Table 3.

\section{Development Scenarios Optimization}

Different completion measures, including perforated completion, conventional fracturing completion and segmented multi-cluster fracturing completion, are analyzed firstly. Then the optimized well group with superior completion are used to optimize different development modes, such as water flooding, succession $\mathrm{CO}_{2}$ flooding and WAG of $\mathrm{CO}_{2}$ flooding. Finally, the parameters, including the formation pressure, production rate, shut-in gas-oil ratio and total gas injection volume, are optimized. Evaluation index is mainly the recovery factor of ten years and the $\mathrm{CO}_{2}$-oil draining efficiency. The $\mathrm{CO}_{2}$-oil draining efficiency is calculated by the following equation.

$$
E_{\mathrm{CO}_{2}}=\frac{T_{\text {oil }}}{T \mathrm{CO}_{2}}
$$

Where, is $E_{\mathrm{CO}_{2}} \mathrm{CO}_{2}$-oil draining efficiency, which is the reciprocal of $\mathrm{CO}_{2}$ utilization factor, is total oil production amount $(\mathrm{t}), \mathrm{T}_{\mathrm{CO}_{2}}$ is $\mathrm{CO}_{2}$ total injection amount $(\mathrm{t})$.

\section{Well completion measures}

In order to study the different horizontal well completions impact on development effect, three scenarios are designed. The first scenario is that the horizontal well is completed by perforating. The second scenario is that the horizontal well is completed by conventional fracturing. The third scenario is that the horizontal well is completed by segmented multi-cluster fracturing. The vertical wells are water injection wells, 


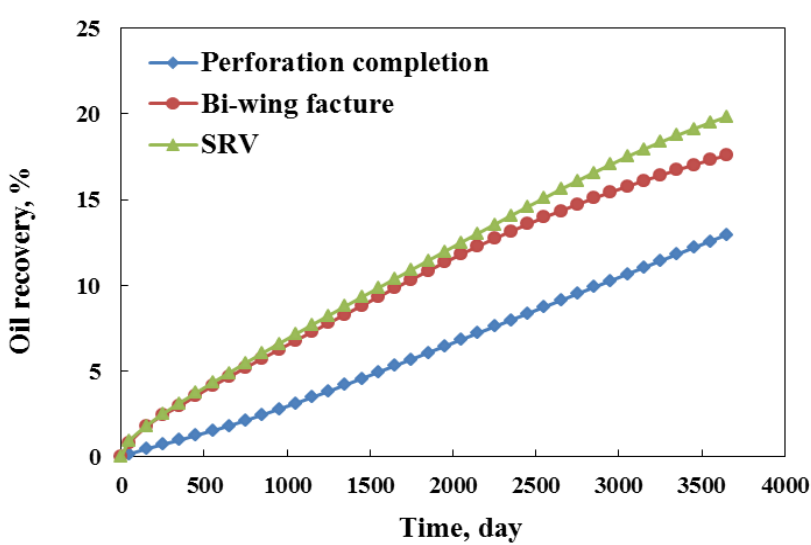

Figure 3: Oil recoveries of different horizontal well completions.

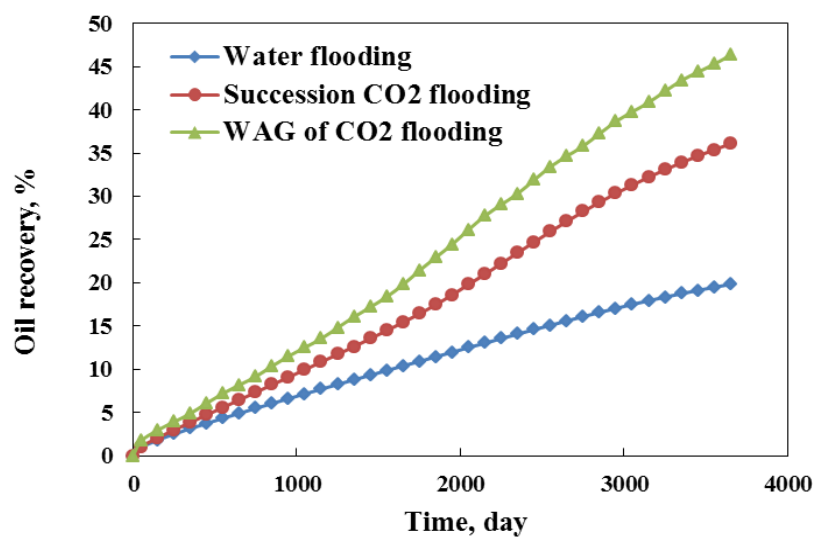

Figure 4: Oil recoveries of different development modes.

the horizontal wells are production wells, and the production control conditions of the three scenarios are the same.

As it can be seen from the Figure 3, the scenario of the horizontal well with SRV has the highest oil recovery, the following is the scenario of the horizontal well with bi-wing fracture, and the scenario of the horizontal well with perforation completion has the lowest recovery. Therefore, the horizontal well with SRV is selected as one of the best well completion measures to develop tight oil reservoir. In the following scenarios, the wells are all volume fractured as wells in model 3 .

\section{Development mode}

The depletion development mode is usually used to develop tight oil reservoir, which is mainly due to the difficulty in injecting an oildisplacing agent to such tight reservoirs. The vertical and horizontal wells after volume fracturing can obtain SRV around them. The permeability and flow capacity of the reservoir have been greatly improved, which makes it possible to inject an oil-displacing agent to develop tight oil reservoir. Therefore, the water flooding, succession $\mathrm{CO}_{2}$ flooding and WAG of $\mathrm{CO}_{2}$ flooding are designed to study their effect on the development tight oil reservoirs. For succession $\mathrm{CO}_{2}$ flooding and WAG of $\mathrm{CO}_{2}$ flooding, the same amounts of $\mathrm{CO}_{2}$ are controlled to inject in these two scenarios.

In Figure 4, the scenario of WAG of $\mathrm{CO}_{2}$ flooding has the highest oil recovery, while the scenario of water flooding has the lowest recovery.
The oil recovery of WAG of $\mathrm{CO}_{2}$ flooding is higher than that of the succession $\mathrm{CO}_{2}$ flooding. One reason is that the same $\mathrm{CO}_{2}$ amounts are injected in these two scenarios, and both of $\mathrm{CO}_{2}$ and water can contribute to oil recover in WAG of $\mathrm{CO}_{2}$ flooding, but there only $\mathrm{CO}_{2}$ contribute to oil recover in succession $\mathrm{CO}_{2}$ flooding. The other reason is that after gas breakthrough, the WAG of $\mathrm{CO}_{2}$ flooding can control the produced gas-oil ratio better than that of succession $\mathrm{CO}_{2}$ flooding. Considering obtaining the same recovery, it requires fewer $\mathrm{CO}_{2}$ amount of the WAG of $\mathrm{CO}_{2}$ flooding than that of succession $\mathrm{CO}_{2}$ flooding, which reduces the cost of gas flooding. Furthermore, the WAG of $\mathrm{CO}_{2}$ flooding is better to maintain formation pressure and to reduce the produced gas-oil ratio, so it is selected as the best development mode (Figure 5).

\section{Production rate}

As the production of horizontal well with SRV is controlled by flowing bottom-hole pressure (FBHP), different production rate can be obtained by adjusting the FBHP. In order to study the impact, 4 scenarios with different FBHP are designed, FBHP of which are $8 \mathrm{MPa}$, 9.3 $\mathrm{MPa}, 10 \mathrm{MPa}$ and $12 \mathrm{MPa}$, respectively.

Figure 6 shows that the higher production rate (the lower the bottomhole pressure) is, the higher the corresponding oil recovery could obtain. But when the FBHP of production well is less than the saturation pressure, the increased of oil recovery is not that obvious, and the $\mathrm{CO}_{2}$ oil draining efficiency is greatly reduced. Also, the gas breakthrough time would become earlier. Furthermore, it is difficult to maintain the formation pressure around the MMP in the later stage. Therefore the FBHP should not be lower than the saturation, in the other words, the production rate should not be too large. Through the comprehensive analysis of the above, it is preferable to control bottomhole pressure at 9.3 $\mathrm{MPa}$, which is little above saturation pressure (9.25 $\mathrm{MPa})$. When the displacement front reaches the SRV of the horizontal well, the $\mathrm{CO}_{2}$ starts to breakthrough, then it should be appropriate to increase the water slug to decrease produced gas-oil ratio and maintain formation pressure.

\section{$\mathrm{CO}_{2}$ injection amount}

Based on these following 10 WAG of $\mathrm{CO}_{2}$ flooding scenarios, the relationship between oil recovery of ten years and $\mathrm{CO}_{2}$ injection amount is obtained. Figure 6 shows that $\mathrm{CO}_{2}$ injection volume is proportional to the oil recovery, the larger the $\mathrm{CO}_{2}$ injection amount is, the higher the oil recovery could obtain.

Ensuring adequate $\mathrm{CO}_{2}$ gas injection amount is the key to improve oil recovery. Figure 6 shows that oil recovery increases with the increasing of $\mathrm{CO}_{2}$ injection amount. But when the $\mathrm{CO}_{2}$ injection amount is larger than $4 \times 104 \mathrm{t}$, the increase of oil recovery is slow. Therefore, the reasonable total injection amount of $4-4.5 \times 104 \mathrm{t} \mathrm{CO}_{2}$ is recommended for this five-spot pattern well group.

\section{Conclusion}

The permeability and flow capacity of the reservoir have been greatly improved after larger scale SRV measures, which makes it possible to inject an oil-displacing agent to develop of tight oil reservoir. The WAG of $\mathrm{CO}_{2}$ flooding has better development effect than water flooding or succession $\mathrm{CO}_{2}$ flooding. The WAG of $\mathrm{CO}_{2}$ flooding can offset the short comings of low oil displacement efficiency of water flooding, and it can also improve the low sweep efficiency of succession $\mathrm{CO}_{2}$ flooding. In order to slow down the speed of the $\mathrm{CO}_{2}$ breakthrough and maintain the formation pressure, it should be appropriate to increase the water 
Citation: Zhao X, Liao X, Wang H (2014) The Research of Gas Flooding of Horizontal Well with SRV in Tight Oil Reservoir. J Pet Environ Biotechnol 6: 197. doi:10.4172/2157-7463.1000197
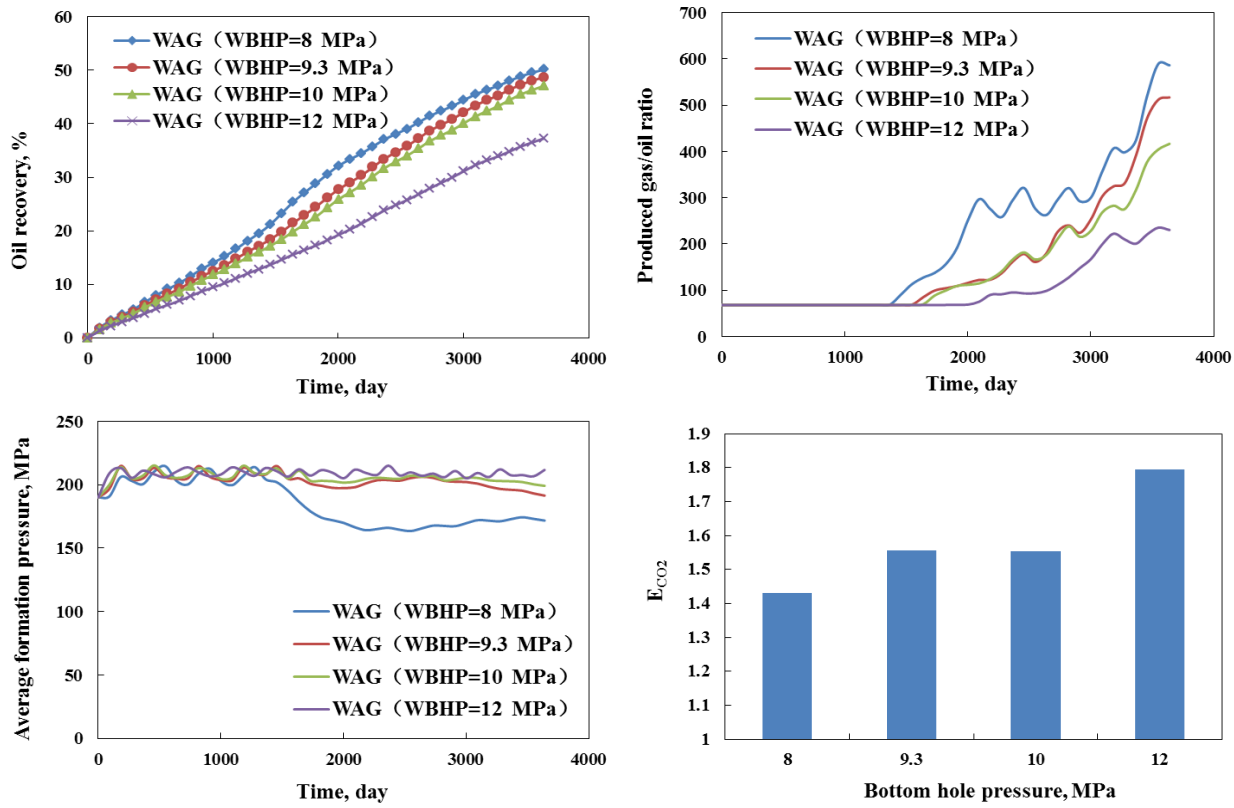

Figure 5: Oil recoveries of different production rate.

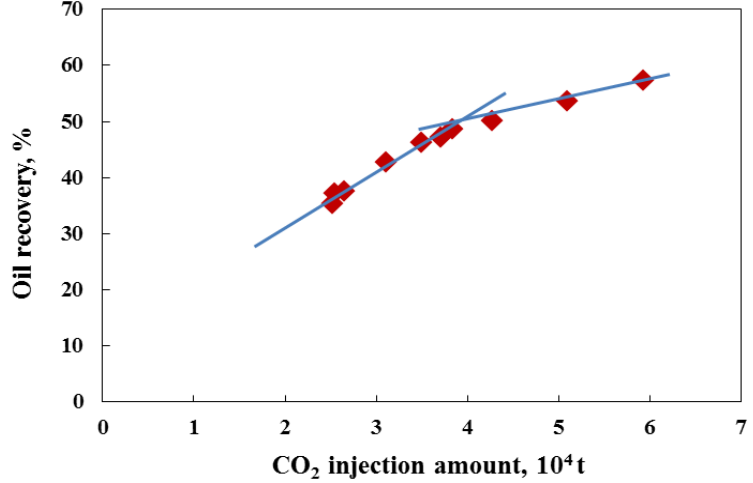

Figure 6: $\mathrm{CO}_{2}$ injection amount vs. oil recovery factor.

slug when the displacement front reaches the SRV of the horizontal wells. The MMP of $\mathrm{CO}_{2}$ and crude oil is a key factor for the WAG of $\mathrm{CO}_{2}$ flooding, it is better to maintain the formation pressure 1-2 MPa higher than MMP. $\mathrm{CO}_{2}$ injection volume is proportional to the oil recovery, but there is an optimal value.

\section{Acknowledgement}

This work was supported by the National Basic Research Program of China "Carbon Dioxide Emission Reduction, Storage and Resource Utilization (973 Program, Grant 2011CB707302)", the Chinese National Major Science and Technology (Projects 2011ZX05016-006 and 2011ZX05009-004-001), and the Specialized Research Fund for the Doctoral Program of Higher Education of China (No 20120007120007).

\section{References}

1. Brohi I, Pooladi-Darvish M, Aguilera R (2011) Modeling Fractured Horizontal Wells As Dual Porosity Composite Reservoirs - Application To Tight Gas, Shale Gas And Tight Oil Cases, SPE Western North American Region Meeting.

2. Zhou W, Gupta S, Banerjee R (2013) Production Forecasting and Analysis for Unconventional Resources, International Petroleum Technology Conference, Beijing, China.
3. Zou C, Zhu R, Wu S (2012) Types, characteristics, genesis and prospects of conventional and unconventional hydrocarbon accumulations: taking tight oil and tight gas in china as an instance. Acta Petrolei Sinica 33: 173-187.

4. Yu W, Sepehrnoori K (2013) Optimization of Multiple Hydraulically Fractured Horizontal Wells in Unconventional Gas Reservoirs, SPE Production and Operations Symposium, Oklahoma, USA.

5. Du C, Zhang X, Zhan L (2010) Modeling Hydraulic Fracturing Induced Fracture Networks in Shale Gas Reservoirs as a Dual Porosity System. International Oil and Gas Conference and Exhibition in China, Beijing, China.

6. Zhao GA (2012) Simplified Engineering Model Integrated Stimulated Reservoir Volume (SRV) and Tight Formation Characterization with Multistage Fractured Horizontal Wells, SPE Canadian Unconventional Resources Conference.

7. Saldungaray PM, Palisch TT (2012) Hydraulic Fracture Optimization in Unconventional Reservoirs, SPE Middle East Unconventional Gas Conference and Exhibition, Abu Dhabi.

8. Wu Q, Xu Y, Wang X (2012) Volume Fracturing Technology of Unconventional Reservoirs: Connotation, Design Optimization and Implementation. Petroleum Exploration and Development 39: 377-384.

9. Suarez M, Vega Velasquez L, Monti LJ (2013) Modeling Vertical Multifractured Wells in Vaca Muerta Shale Oil Play, Argentina, SPE Unconventional Resources Conference-USA, The Woodlands.

10. Ghaderi SM, Clarkson CR, Chen S (2012) Evaluation of Recovery Performance of Miscible Displacement and WAG Process in Tight Oil Formations, SPE/ EAGE European Unconventional Resources Conference and Exhibition, Vienna, Austria.

11. Song C, Yang DT (2012) Optimization of CO2 Flooding Schemes for Unlocking Resources from Tight Oil Formations, SPE Canadian Unconventional Resources Conference, Calgary. 